\title{
Research on Complementary of New Energy for Generation
}

\author{
Dan Li, Haiming Zhou, Fumin Qu \\ China Electric Power Research Institute, Beijing, China \\ Email: woandyu@126.com
}

Received April, 2013

\begin{abstract}
Limited conventional energy and environmental issues have become increasingly prominent, so it has been more national attention to environmental protection and renewable new energy. The world's growing demand for energy, and the limited reserves of conventional non-renewable resources, mankind is facing a serious energy crisis. Coupled with the use of fossil fuels has brought serious environmental pollution problems, so the transition energy development way imminent, the need to be constantly developed and developing green renewable energy generation technologies.
\end{abstract}

Keywords: Energy; Environmental Pollution; Green Renewable Energy

\section{Introduction}

The world foot of the main power of the growing demand for energy, consume large amounts of coal and oil thermal power, while the contribution for the development of the national economy and the improvement of people's living standards, a lot of power, a lot of dust and smoke emissions, sulfur dioxide and other atmospheric pollutants, causing huge damage to our ecological environment. On the other hand, coal and oil reserves are limited, and the tighter supply. The limited reserves of conventional non-renewable resources, mankind is facing a serious energy crisis. From the protection of the ecological environment and energy consumption, we need to find new energy sources to replace conventional energy. Imminent transformation of energy development, need to be constantly developed. China has a wealth of new energy and renewable energy resources, mainly solar, wind, hydro.

\section{Research Status at Home and Abroad}

Solar new energy as a clean and pollution-free one, and has broad prospects for development in China's solar power photovoltaic-based. By the end of 2010, China's cumulative PV capacity of 860,000 kilowatts, including newly added 580,000 kilowatts, solar power projects currently under construction total size of up to 1 million kilowatts, the cumulative solar power capacity will reach 10 million kilowatts by 2015. However, the polycrystalline silicon solar cell is only in a small number of trial production stage. China's PV production and research and development, there is a great gap compared with foreign countries, solar power is still in the small and medium-scale use of stage. Solar applications in Japan, a shortage of resources, Japan has been actively developing solar, wind, nuclear energy and other new energy sources, the use of biomass power generation, waste power generation, geothermal power and the production of fuel cells as a new energy, especially high hopes for the development and utilization of solar energy. Since 2000, solar photovoltaic, solar cell production for many years ranked first in the world, accounting for about half of the world's total output of. Wind energy is currently more mature a technology developed rapidly, the market value has been accepted by the people of clean energy. Wind energy has become an important part of the new energy plan for the U.S. government.

American Wind Energy Association, said New 8.35 GW wind power capacity in 2008, total production capacity has reached $25.1 \mathrm{GW}$, accounting for $1 / 5$ of global wind power, become the first in the world wind power. Wind energy resources have characteristics of randomness [1], intermittent, unpredictable nature and can not be stored, etc., tend to access the power system will bring greater harm [2-4] (such as the instability of the system is running, etc.), resulting in more wind power in the actual operation is limited to the Internet, has not been to maximize the use of wind power resources and social benefits [5-7]. The solution to this problem lies in how to control the power characteristics of wind power in the power system access, effective way of performance in wind power storage or complementary with energy joint op- 
eration and grid. The feng shui complementary power generation system is the organic combination of wind power generation system with the hydroelectric system with scheduling [8], when random fluctuations in the output of the wind farm to the grid, hydropower can quickly adjust the output of the generator output to compensate for the wind farm [9]. In recent years, the existing literature has studied wind water complementary joint optimization run, the use of pumping energy storage power plants, wind power and run complementary example optimized computing literature [10-12], especially more, but the pumping energy storage power stationbuilding restrictions of natural conditions and requires a lot of investment. General regulation of hydropower and wind power complementary the literature relatively small and subject to geographical restrictions, [13] proposed using wind power / utilities complementary solve the reliability of power supply problems in the cold northern areas, and increase the economic efficiency of the system. [14] Proposed to solve the problem of power peaking and winter stable supply build wind, water and solar systems in Xinjiang. [15] With a specific example reveals the complementary characteristics of hydropower hydropower hydropower its power to support its capacity to support wind power and wind power wind power. If wind power configuration corresponding energy storage device (battery), with water and electricity the complementary to run (referred to as the wind build a hydropower complementary), the effective control of the power characteristics of the complementary system more secure and stable access to the grid, to improve the delivery of wind powercapacity, will make green energy to create more value.

Cold regions in northern China at the same time there is rich in hydropower resources and wind energy resources, from a seasonal point of view, winter and spring the water level of the reservoir is low, insufficient output of hydropower, when the wind speed of the wind farm, able to assume moreload. Wind speed in summer and autumn, the lower output of the wind farm, at this time it is the abundant rainfall, hydropower can bear the load, so precisely wind power hydropower season on complementary. In addition, small hydropower short-term volatility, the runoff in a day and night is basically uniform, while the short-term volatility of wind power is great, so that can reflect the complementary nature of wind power and hydropower [15]. In order to make effective use of wind energy, an energy storage device needs to be configured to reduce the supply of the electricity grid in the hydropower complementary supply of wind power, increase the effectiveness of the complementary system. Storage of wind energy [16], and the battery has a high efficiency, simple, reliable, high discharge power, quick charging, long cycle life, light weight, etc., to complete the storage of excess wind power to supply the load. Select the battery to store excess wind energy on the feng shui complementary system and provide power to the load when necessary.

Hydro power generation will be the impact of the flood season and non-flood season. Flood season and non-flood hydropower optimization run around the nature of hydropower peaking hydropower generating capacity of wind power consumptive ability to maximize the optimization model to carry out comprehensive consideration. Therefore, the standard water and electricity to run the merits of large-scale wind power access grid case consists of two parts:

$$
E=E_{H}+E_{W}
$$

Formula: $E$ is Target power, $E_{H}$ is Hydropower generating capacity, $E_{W}$ is Hydropower peaking power to the assimilative capacity of wind power.

Judging from the different periods of reservoir inflow characteristics, hydropower annual run can be divided into the flood season and non-flood season run.

\section{Research on the Non-flood Season Run}

Non-flood season have when hydropower plays a role in peak shaving, and wind power for the grid consumptive conditions. Run water and electricity in the grid load chart position, the peak load hydropower assumed more and more flat reserved for other power assumed power grid load on the grid clean energy consumptive conditions more favorable, but non-flood season by available water and hydropower installed capacity constraints, limited water and electricity in the grid during peak hours assumed power, hydropower peaking to eliminate the ability of wind power and hydropower generating capacity, hydropower installed capacity, power generation head, reservoir utilization requirements, as well as the power grid operation requirements related. Each charge relationship is calculated as follows:

$$
\begin{gathered}
E_{H, t}=K Q_{t} \mathrm{~h}_{t} \Delta t \\
E_{C H, t}=E_{H, t}-P_{b, t} \Delta t \\
E_{P L, t}=\left(P_{\max }-P_{b, t}\right) \Delta t
\end{gathered}
$$

Formula: $E_{H, t}$ is Generating capacity of hydropower $t$ periods, $K$ for hydropower output coefficient, $Q_{t}$ is for $t$ periods generation flow, $h_{t}$ is the period $t$ Hydropower average power head, $\Delta t$ is The number of hours of the time period $t, E_{C H, t}$ is period $t$ hydropower generating capacity net of minimum power after electricity, $P_{b, t}$ is the $t$ periods hydropower lowest output, $E_{P L, t}$ is The hydropower $t$ time adjustable power, $P_{\max , t}$ is the period $t$ hydropower expected to contribute, Size and average hydropower power head units available capacity and 
maximum contact line.

\subsection{Non-the Flood Season Hydroelectric Peaking Elimination of Wind Power Capacity}

According to the size of $E_{C H, t}$, Calculate the hydropower $t$ periods peaking consumptive wind power capacity charge $E_{W, t}$ Can be divided into two kinds:

$$
E_{W, t}=\left\{\begin{array}{l}
E_{C H, t}, E_{C H, t}<\frac{E_{P L, t}}{2} \\
E_{P L, t}-E_{C H, t}, E_{C H, t} \geq \frac{E_{P L, t}}{2}
\end{array}\right.
$$

Visible, more non-flood hydropower generating capacity of peaking to consumptive, more wind power more favorable. Inevitably must bear trough power generation capacity over peak demand for electricity adjustable grid load when the hydropower $t$ periods. The hydropower generating capacity is more and more unfavorable to the contrary, the power peaking. This was:

$$
E_{W, t}=\min \left(E_{C H, t}, E_{P L, t}-E_{C H, t}\right)
$$

\subsection{The Hutchison and Massive New Energy Access Non-flood Hydropower Optimal Operation Mode}

As is shown in Figure 1, when the generating capacity to reach $E_{H, t}$, Hydropower peaking reaches a maximum contribution of electricity by wind power consumptive. Theoretically, when $E_{H, t} / E_{H, t}^{\prime}$, and $E_{H, t}=E_{W, t}$ grid clean energy dissipation Granada to the best point. However, due to the water for reservoir operation with a lag, the best point of dynamic optimal point, need to be placed throughout the scheduling period to the consolidated balance.

Therefore, the non-flood season (in $T_{L}$ ) annual run model for hydropower:

$$
T_{L}=\max \sum_{t \in T L}\left(E_{H, t}+\min \left(E_{C H, t}, E_{P L, t}-E_{C H, t}\right)\right)
$$

\subsection{The Flood Season of Hydropower Optimal Operation}

Since the flood season more runoff, and subject to the constraints of limited water level of reservoir flood season easily lead to disposable water, hydro mandatory participation peaking requirements to reflect the power grid, reservoir the annual operation mode making the introduction of daily load rate power peaking hydropower to participate describe, Hydropower $t$ periods daily load expressed as:

$$
\gamma_{t}=\frac{P_{t}}{P_{\max , t}}
$$

where: $P_{t}$ is the average output of the hydropower $t$ periods. The visible daily load rates reflect the size of the contribution of hydropower flood season to participate peaking. To increase in terms of hydropower, flood season peaking, divided into the following two situations:

1) To allow a regulating storage reservoir ahead of pre-vent some water, will inevitably lead to reduced hydropower generation capacity.

2) Reservoir the abandoned water peaking, and the inevitable loss of some water resulting in reduced hydropower generation capacity, the measures equivalent consumptive wind power to give up part of the hydropower generating capacity.

The flood season of hydropower generating capacity should be:

$$
E_{H, t}=\min \left(P\left(Q_{t}\right) \Delta t, P_{\text {max }, t} \gamma_{t} \Delta t\right)
$$

where: $P\left(Q_{t}\right), Q_{t}$ corresponds to the hydropower generation water flow output.

Flood season hydroelectric peaking assimilative capacity of wind power electricity:

$$
E_{W, t}=\left(P_{\max , t}\left(h_{t}\right) \gamma_{t}-P_{b, t}\right) \Delta t-E_{C H, t}
$$

Therefore, the flood season (in $T_{H}$ ) build the target function is as follows:

$$
T_{H}=\max \sum_{t \in T L}\left(E_{H, t}+E_{W, t}\right)
$$

\section{Hydropower Peaking Contribution to the Power of the New Energy Consumptive Best Balance Analysis}

Overall, the flood season to consider seeking the best balance of hydropower generation and hydropower peaking assimilative capacity of wind power electricity daily load rate constraints premise. Under normal circumstances, is to deal with the impact of wind power randomness of the grid, the grid is usually configured according to the same capacity with wind power conventional energy. Similarly, through the model theory analysis shows that, net power, hydropower generating capacity and adjustable power equal contribution of wind power consumer is satisfied most favorable. As is shown in Figure 1, $E_{H, t}=E_{W, t}$, the grid is the best balance of clean energy dissipation Granada. But this time is not the best clean energy generating capacity to achieve hydropower the largest contribution to the entire power grid clean energy consumptive target.

The objective function must also meet the following constraint conditions, 
1) The water balance constraints:

$$
\begin{aligned}
& W_{t+1}=W_{t}+\left(Q_{i n, t}-Q_{\text {out }, t}-\Delta Q_{t}\right) \Delta t \\
& Q_{\text {out }, t}=Q_{g, t}+Q_{e, t}+Q_{s, t}
\end{aligned}
$$

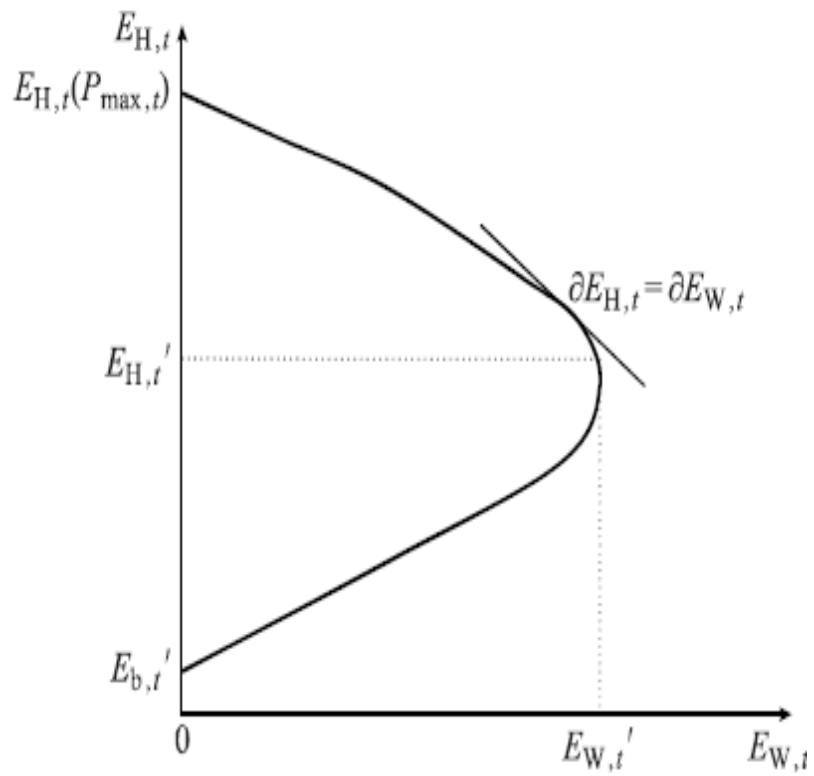

Figure 1. Non-flood hydropower generating capacity and peaking power capacity of wind power to dissolve the relationship.

where: $W_{t}$ and $W_{t+1}$, respectively, for the the $t$ periods early and late-period reservoir storage, $Q_{i n, t}$ and $Q_{\text {out,t, }}$, respectively, for the period $t$ average inbound and outbound flow, $\Delta Q_{t}$ period $t$, the average loss (evaporation, leakage, etc.) flow, $Q_{g, t}, Q_{e, t}, Q_{s, t}$ respectively the time $\mathrm{t}$ average gate sluicing flow, generating traffic, comprehensive flow.

2) Water availability constraints

$$
\sum_{i=1}^{T} Q_{i n, t} \Delta t+\Delta W=W
$$

where: $\Delta W$ is the storage capacity of the reservoir operation period; $W$ scheduler period water availability, specific to a given year fixed runoff is a constant

3) The water level on the lower limit constraints

$$
Z_{\text {min, } t} \leq Z_{t+1} \leq Z_{\text {max }, t}
$$

wherein: $Z_{\min , t}, Z_{t+1}, Z_{\max , t}$ respectively, for the end of the period $t$, the minimum water level, period level, the highest water level of the period.

4) Comprehensive utilization of the flow limit constraints

$$
Q_{\text {min,t }} \leq Q_{\text {out }, t} \leq Q_{\text {max }, t}
$$

where: $Q_{\min , t}$ and $Q_{\max , t}$, respectively, for the period $t$ minimum library traffic and outbound flow.

\section{Conclusions}

China's future sustainable energy development needs to be strong and smart grid support. Mostly with the conditions for the development of large-scale hydro, wind, solar and other clean energy and new energy, But far from load centers, the need for large-scale, long-distance transmission, the implementation of a wide range of energy optimal allocation of resources. So building a strong grid structure is the focus of China's smart grid development. In long-term point of view, the development of smart grid not only enhances the level of energy security, but also guides and changes the user's energy consumption habits, improve the efficiency of energy utilization. Rely on a strong and smart grid intelligent allocation of resources to become a key factor to enhance the sustainable development of China's energy.

\section{REFERENCES}

[1] H. H. Zhou and B. Tran, "Composite Energy Storage System with Flexible Energy Management Capability for Micro-grid Applications,” Energy Conversion Congress and Exposition (ECCE), 2010, pp. 2558-2563.

[2] P. Juang and Kollmeyer, "System Identification Based Lead Acid Battery Online Monitoring System,” Energy Conversion Congress and Exposition(ECCE), 2010, pp. 3903-3910.

[3] C. Stummer and K. Heidenberger, "Interactive R \& D Portfolio Analysis with Project Interdependencies and Time Profiles of Multiple Objectives," IEEE Transactions on Engineering Management, Vol. 50, No. 2, 2003, pp. 175-183.doi:10.1109/TEM.2003.810819

[4] Y. P. Yu, M. Yong, L. Chen, et a1., "Analysis of Forced Power Oscillation Caused by Continuous Cyclical Load Disturbances," Automation of Electric Power Systems, Vol. 34, No. 6, 2010, pp. 7-11.

[5] Z. Y. Han, R. M. He, J. Ma, et a1., "Comparative Analysis of Disturbance Source Inducing Power System Forced Power Oscillation," Automation of Electric Power Systems, Vol. 33, No. 3, 2009, pp. 16-19.

[6] Y. P. Yu, Y. Min, L. Chen, et a1., "Disturbance Source Location of Forced Power Oscillation Using Energy Functions,” Automation of Electric Power Systems, Vol. 34, No. 5, 2010, pp. 1-6.

[7] D. G. Yang, J. Y. Ding, H. Zhou, et a1., "Mechanism Analysis of Low - Frequency Oscillation Based on WAMS Measured Data," Automation of Electric Power Systems, Vol. 33, No. 23, 2009, pp. 24-28.

[8] D. J. Yang, J. Y. Ding, J. Y. Li, et aI., “Analysis of Power System Forced Oscillation Caused by Asynchronous Parallelizing of Synchronous Generators," Automation of Electric Power Systems, Vol. 35, No. 10, 2011, pp. 99-103.

[9] Y. Yang, F. Wen, L. Li, et a1., “Coordinated Model for Available Transfer Capability Decision-making Employ- 
ing Multi-objective Chance Constrained Programming," Automation of Electric Power Systems, Vol. 35, No. 13, 2011, pp. 37-43.

[10] M. Wang and M. Ding, "Probabilistic Calculation of Tota1 Transfer Capability Including Large Scale Solar Park," Automation of Electric Power Systems, Vol. 34, No. 7, 2010, pp. 31-35.

[11] S. K. Chung, "Phase-Locked Loop for Grid-Connected Three-Phase Power Conversion Systems," IEE Proc eedings-Electric Power Applications, Vol. 147, No. 3, 2000, pp. 213-219.doi:10.1049/ip-epa:20000328

[12] K. D. Zhu, Y. H. Song, Z. F. Tan, et al., "China Wind Power Integration Status Quo and Its Benefit to Energy Saving and Emission Reduction,” Electric Power, Vol. 44, No. 6, 2011, pp. 67-70.

[13] Z. H. Liu, L. Chen and Y. Min, “A Practical En- ergy-saving Generation Dispatching Model Integrated with Wind Power ,” Electric Power, Vol. 44, No. 6, 2011, pp. 52-57.

[14] X. Z. Dai, Y. H. Shi, Z. X. Lu, et al., "Impact of Large-scale Wind Power on Operation Stability and Security of Connected Jiangsu Grid,” Electric Power, Vol. 44, No. 6, 2011, pp. 42-47

[15] F. Zhang, M. X. Li, G. W. Fan, et al., "Transient Voltage Stability Study about a Regional Grid Integrated with Wind Power,” Electric Power, Vol. 44, No. 9, 2011, pp. 17-21.

[16] G. L. Liu, J. J. Cai and W. Q. Wang, "Impacts of Grid Connection and Disconnection of Wind Turbines on System Operation and CopingSstrategies," Electric Power, Vol. 44, No. 4, 2011, pp. 7-10. 